\title{
HERNIORRAFIA PERINEAI EM CÃES - ANÁLISE DE 35 CASOS
}

\author{
PERINEAL HERNIORRHAPHY IN DOGS - ANALYSIS OF 35 CASES
}

\author{
Alceu Gaspar RAISER'
}

\begin{abstract}
RESUMO
Entre janeiro de 1980 e dezembro de 1992 foram atendidos, pelo autor, 35 cães portadores de hérnia perineal. Os animais fizeram parte da casuística do Hospital de Clínicas Veterinárias da Universidade Federal de Santa Maria. A prevalência da hérnia foi de $0.5 \%$ no período. As complicaçōes encontradas foram retroflexão vesical, aumento de volume da próstata, divertículo ou dilatação retal, tecido adiposo retroperitoneal necrosado e efusão serosa ou serossanguínea. Foram recuperados $85.68 \%$ dos pacientes. $O$ sucesso da cirurgia depende da desobstrução dos tratos digestivo e urinário. adequada obliteração da abertura perineal e controle do tenesmo e infecção.
\end{abstract}

UNITERMOS: Hérnia: perínco: cirurgia; cães; herniorrafia

\section{INTRODUÇÃO}

A hérnia perineal tem sido denominada enfermidade dos cães machos $^{4,11}$. A prevalência é maior a partir de meia idade ${ }^{14}$, dos sete aos onze ${ }^{6}$ ou sete aos quatorze anos ${ }^{13}$.

ARCHIBALD; SUMNER-SMITH' (1974) sugeriram que a hérnia perineal esteja associada ao aumento de volume da próstata, pois é um achado comum nos cães com desequilíbrio hormonal.

MANN et al. ${ }^{10}$ (1989) analisaram as concentrações de testosterona e 17-beta estradiol em cães portadores de hérnia perineal. Verificaram que não diferem daquelas em animais sadios com a mesma idade. Concluíram que a orquiectomia não deve ser recomendada para tratamento da hérnia perineal, a não ser que seja identificado um fator contribuinte, como prostatomegalia, responsivo à castração.

KRAHWINKEL ${ }^{9}$ (1983) estudou a influência de enfermidades retais em quatro cães com hérnia perineal. Relatou que são frequientes anormalidades do reto como saculação, dilatação, flexura ou desvio. Segundo ele, todos os cães com estas patologias têm hérnia perineal, embora o inverso nem sempre seja verdadeiro.

MATERA $^{11}$ (1975) associou a atrofia do músculo elevador do ânus e o aumento na pressão abdominal como fatores etiológicos de hérnia perineal.

O conteúdo herniário mais encontrado na região perineal tem sido a saculação retal, tecido adiposo retroperitoneal, alça intestinal, partes do epíploo, bexiga e/ou próstata ${ }^{4,6.14}$.
DALECK et al. ${ }^{6}(1992)$ citaram que a bexiga retroflexionada foi o principal conteúdo em treze cães portadores deste tipo de hérnia. SPICCIATI ${ }^{13}$ (1971) descreveu dez casos de hérnia perineal cujo conteúdo eram bexiga e próstata aumentadas de volume.

Encarcerada, a bexiga $\mathrm{em}$ retroflexão sofre progressiva distensão, agravando o quadro de retenção urinária. Em casos de obstrução e distensão prolongadas a tendência é evoluir até ruptura ${ }^{14}$.

KAUTH $^{8}$ (1985) fez um estudo de 170 casos de hérnia perineal em cães com idade média de 8,6 anos e verificou incidência bilateral em 145 deles. Em todos os casos havia dilatação retal concomitante. Foi encontrada enfermidade prostática em 142 cães, caracterizada por hipertrofia em 139.

O sinal clínico mais frequiente na hérnia perineal é o tenesmo associado à dificuldade de evacuação e/ou micção ${ }^{4.6 .11 .14}$. A estrangúria pode ocorrer associada com patologia prostática ou retroflexão da bexiga e próstata

A drenagem vesical deve ser feita por sondagem uretral ${ }^{13}$ ou cistocentese com agulha fina, em caso de retroflexão. A seguir é feita redução da hérnia por compressão e instituída fluidoterapia para restabelecer a diurese e combater a uremia pós-renal ${ }^{3.4 .5}$.

Nas hérnias perineais com presença de fezes no reto devem ser feitas remoção digital, emolientes fecais e enemas ao menos 18 a $24 \mathrm{~h}$ antes da cirurgia ${ }^{4.5 .13}$. 
BELLENGER ${ }^{20}$ (1980) estudou 35 cães portadores de hémia perineal. Em 32 deles efetuou redução cirúrgica por meio de sutura do diafragma pélvico ou incorporação do ligamento sacrotuberal.

Após anestesia, o paciente de hérnia perineal deve ter os sacos perineais esvasiados, ser posicionado em decúbito esternal com o quadril elevado e a cauda tracionada cranialmente. Após anti-sepsia deve ser feita sutura em bolsa de tabaco ao redor do ânus ${ }^{2.4 .5}$. SPICCIATI ${ }^{13}$ (1971) preferiu o posicionamento em decúbito dorsal, em plano inclinado, com os membros posteriores tracionados cranialmente.

A abordagem cirúrgica da hérnia perineal deve ser sobre o maior eixo da herniação, lateral ao ânus ${ }^{4.5}$, iniciando junto à inserção da cauda e estendendo-se em direção à tuberosidade isquiática ${ }^{13}$. Durante o ato operatório é recomendado gotejamento venoso de solução hidroeletrolítica balancca$\mathrm{da}^{2}$. Nas hérnias bilaterais é recomendado intervalo de 4 a 6 semanas, entre cada intervenção, pois a reparação bilateral simultânea submetc o esfíncter externo do ânus à intensa tensão ${ }^{4.5}$.

O fio de sutura mais utilizado na redução de hérnias perineais tem sido o categute cromado $^{2,4.5 .6}$.

A recidiva é uma complicação pós-cirúrgica relativamente comum, variando de $15,4 \%^{2}$ a $29,8 \%$. WHITE; HERRTAGE $^{14}$ (1986) consideraram fundamental a cirurgia com sucesso e a eliminação do tenesmo para evitar recidivas. KRAHWINKEL ${ }^{9}$ (1983) citou que a correção de alteraçōes anatômicas do reto ć importante para prevenir a recidiva da hérnia, a qual ocorre devido ao tenesmo. MATERA "' (1975) salientou que a hemioplastia é o tratamento definitivo,porém está subordinada à restauração anatômica perfeita da região e correção do fator etiológico.

BELLENGER ${ }^{2}$ ( 1980) recomendou usar antibiótico, como a ampicilina ou amoxicilina, por 3 a 5 dias para evitar infecção.

Revisando a literatura indexada, a partir de 1970, foram encontrados poucos artigos sobre hérnia perineal, publicados no Brasil ${ }^{611.13}$. Assim, visando divulgar a casuística em Santa Maria, e os aspectos da conduta terapêutica, são relatados 35 casos desta patologia em cães.

\section{MATERIAL E MÉTODO}

Foram estudados 35 cães portadores de hérnia perineal, machos, registrados no Hospital de Clínicas Veterinárias da Universidade Federal de Santa Maria e operados pelo autor, no período de janeiro de 1980 a dezembro de 1992. Dos prontuários foram colhidos dados relativos à anamnese, exame físico, conduta cirúrgica e avaliação pós-operatória. Nos animais apresentando conteúdo na ampola retal, além da administração de emolientes, que foi iniciada 24 a 48 horas antes da cirurgia, foi efetuada remoção digital das fezes. Naqueles com bexiga retroflexionada foi feita sondagem vesical. Em alguns cães foi necessária a cistocentese perineal com agulha $30-10$, seguida de redução pela taxe indireta. A punção foi precedida de tricotomia e anti-sepsia.

Após a drenagem da urina e fixação de sonda uretro-vesical, foi iniciada fluidoterapia venosa com solução de Ringer lactato de sódio. O volume diário foi equivalente à necessidade basal $(50 \mathrm{ml} / \mathrm{kg} /$ dia) mais a compensação da depleção MICHELL et al. ${ }^{12}$ (1991). Nos casos de uremia e vômito foi reposto também o equivalente às perdas gastrintestinais.

A tricotomia foi feita em todo o períneo uma hora antes da cirurgia. A seguir, os animais foram tranquilizados com maleato de acepromazina $(0,2 \mathrm{mg} / \mathrm{kg})$ intramuscular e submetidos à indução anestésica com tiopental sódico (10mg/ $\mathrm{kg}$ ), intravenoso. A manutenção foi feita com halotano. Em todos os animais foi procedida intubação orotraqueal.

Após anestesia, os animais foram contidos na mesa cirúrgica em decúbito dorsal, com os membros pélvicos tracionados cranialmente e a cauda presa em plano inferior ao ânus.

Foi feita anti-sepsia e delimitação da área operatória por panos de campo e adaptado tampão de gaze ou sutura em bolsa de tabaco ao redor do ânus. Nas hérnias unilaterais foi feita abordagem por incisão látero-obliquada ao ânus, sobre o saco herniário e nas bilaterais uma a cada lado, convergindo para o escroto de modo a formar um $V$ (Fig. 1). As incisões foram aprofundadas através da tela subcutânea e fáscia perineal, quando identificada, para expor o conteúdo herniário (Fig. 2). Nos cães com hérnia bilateral o retalho foi rebatido em direção ao ânus para permitir ampla exposição do períneo.

Na reduçāo da hérnia, as vísceras viáveis foram repostas para as cavidades abdominal ou pélvica, a efusão drenada quando presente, e o tecido alterado excisado. Em oito cães com prostatomegalia (Fig. 3) foi efetuada prostatectomia pela técnica descrita por SPICCIATI ${ }^{13}$ (1971) e JOHNSTON; ARCHIBALD $^{7}$ (1974). A anastomose término-terminal da uretra foi feita com categute cromado 4-0 agulhado, em pontos isolados, e foi mantida sonda uretral por 48 a 72 horas. Estes animais não foram castrados. Em outros três, também com próstata aumentada de volume, foi feita a redução da hémia e orquiectomia bilateral (Tab. 2).

Nos cães com divertículo retal foi efetuada excisão proctoplástica da saculação e, naqueles portadores de dilatação retal, proctorrafia para diminuição do lume. Nestes foram distribuídos pontos tipo plicatura ao longo da dilatação. Na correção de ambas as patologias as suturas foram feitas com mononáilon 3-0. 


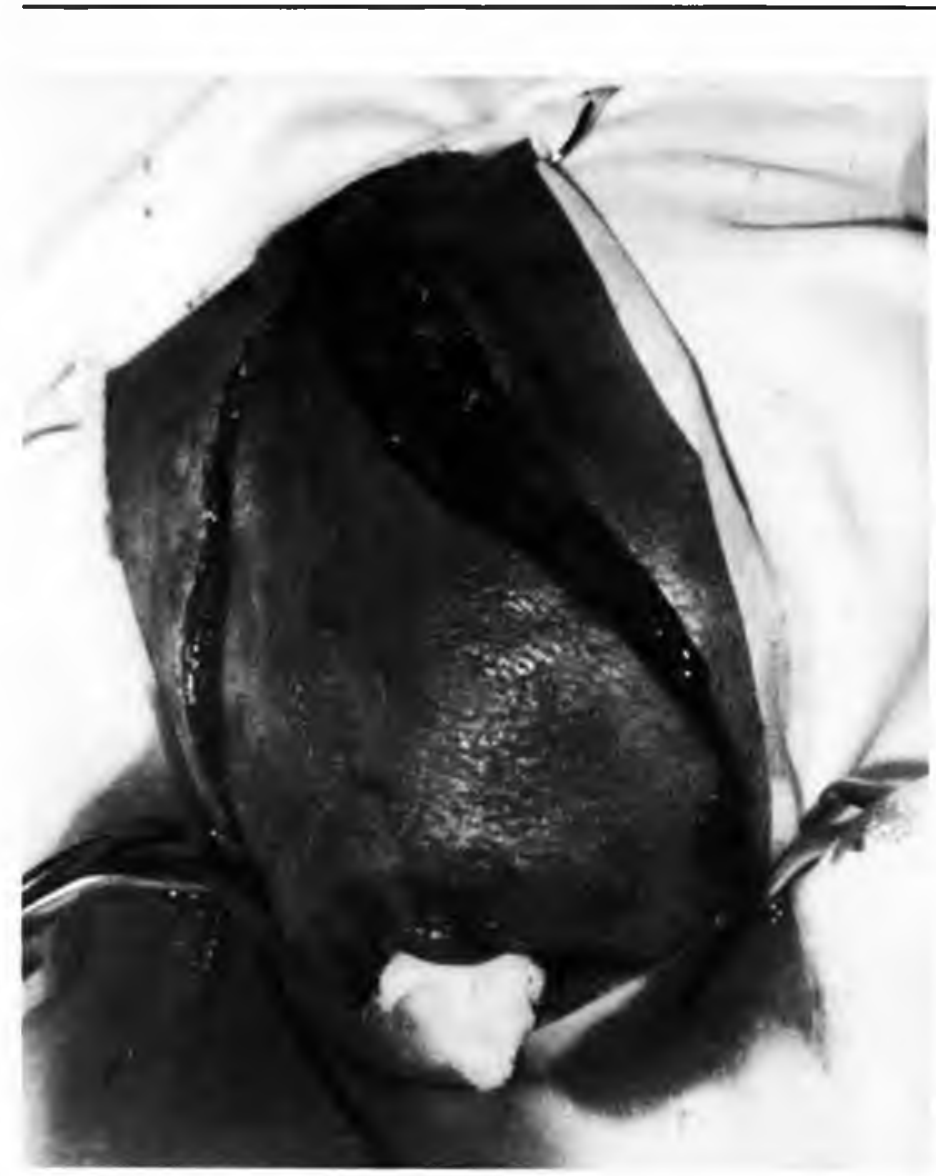

\section{FIGURA I}

A presentação da abordagem em V. para redução da hérnia perineal bilateral. com o cão posicionado $\mathrm{cm}$ decúbito dorsal e os membros pélvicos tracionados cranialmente.

\section{FIGURA 2}

Visualização parcial do conteúdo herniário (bexiga) após incisão cutânea. na abordagem bilateral do períneo de um cão. Observe-se a ausência de fascia perineal e de identificação de músculos próprios do períneo.

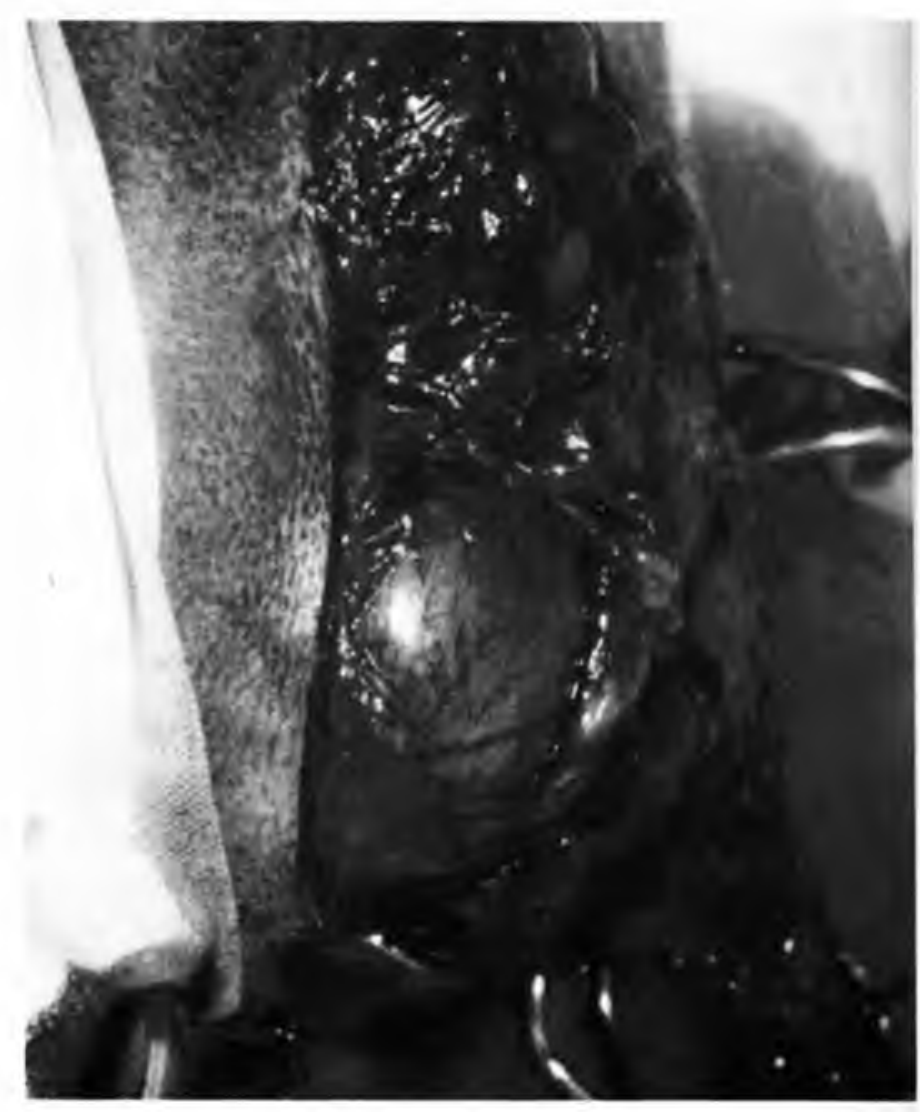




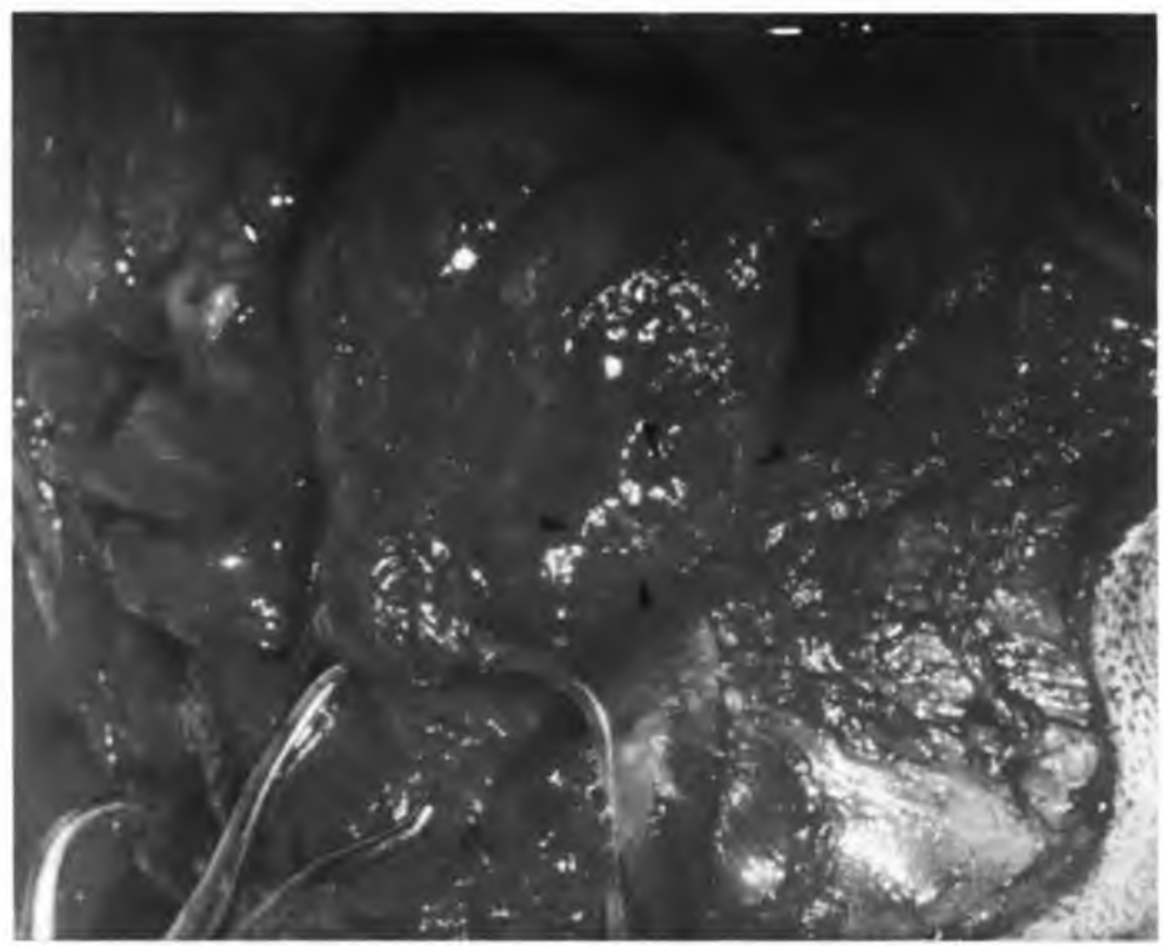

\section{FIGURA 3}

Aspecto da próstala cística (setas) com volume aumentado em um cão portador de hérnia perineal bilateral.

\section{FIGIK:I +}

llustração da área perincal, após herniorratia bilateral, em um cão submetido à prostatectomia, sem orquiectomia.

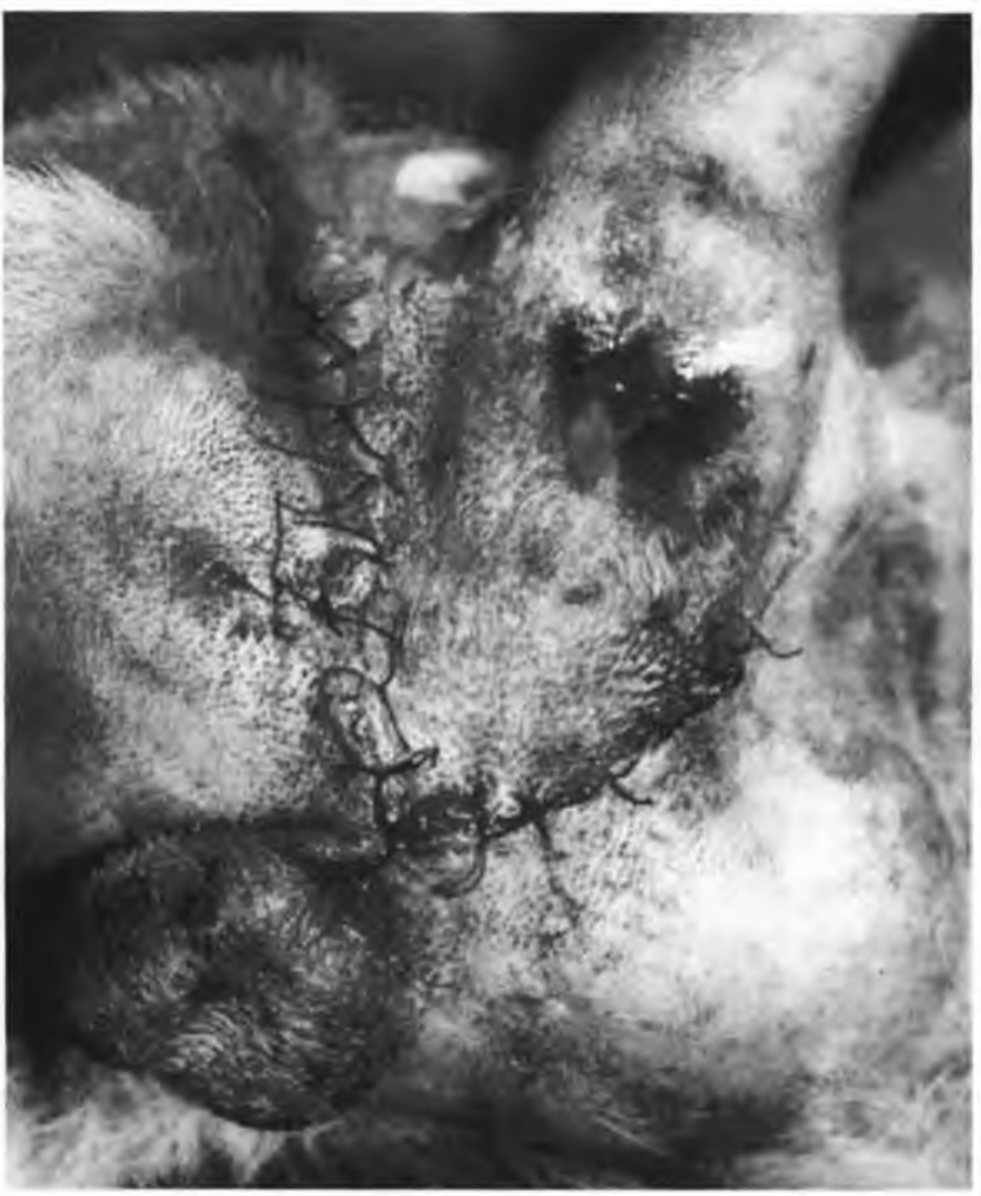


A hemiomatia perineal foi efetuada com fio mononáilon ou poliéster trançado siliconizado ou categute cromado ou ácido poliglicólico, em diâmetros variáveis de 2-0 a 3-0, dependendo do porte físico do animal. Os pontos de sutura foram tipo Wolff, entre o ligamento sacro-tuberal e o esfíncter externo do ânus. Na fáscia perineal, quando identificada, foram dados pontos de reforço. Após sutura da pele com náilon 3-0, foi removida a sutura em bolsa de tabaco ao redor do ânus ou o tampão. adaptados ao início da intervenção (Fig. 4).

Durante a cirurgia, a ferida operatória foi irrigada treqüentemente com solução) salina isotônica à temperatura a) redor de $37^{\prime \prime} \mathrm{C}$

Em todos os cães foi utilizado antibiótico 30 minutos antes da cirurgia e a cada 6 h no primeiro dia, na forma de ampicilina sódica ( $20 \mathrm{mg}$ por $\mathrm{kg}$ ), via intravenosa. A partir do segundo dia foi feita administração de ampicilina benzatínica, intramuscular, a cada 24 h ou amoxicilina oral, a cada 8 horas, durante 5 a 7 dias.

No pós-operatório foi prescrita alimentação pastosa c óleo mincral* (5-10ml/dia), via oral, para favorecer o trânsito digestivo. Foi recomendado repouso absoluto. A sutura cutânea foi removida entre o $7^{\circ}$ e $10^{\circ}$ dias de pós-operatório, quando cada paciente foi reavaliado com liberação ou não das restrições impostas no pós-operatório imediato. O período de acompanhamento dos animais variou de 4 meses a 4 anos.

\section{RESULTADOS E DISCUSSÃO}

Dos 35 cães portadores de hérnia perineal, vinte $(57,14 \%)$ apresentaram prevalência bilateral (Tab. 1), oito $(22,58 \%)$ do lado esquerdo e sete ( $20 \%$ ) do lado direito (Tab. 2). Verificase que a maior incidência da hérnia foi bilateral.à semelhanca dos resultados encontrados por KAUTH ${ }^{8}$ (1985). Considerando esta prevalência e a recidiva contralateral cm três cães (Tab. 2), recomenda-se avaliar todo o períneo quando da inspeção pré-operatória. para identiticar possível enfraquecimento anatômico e predisposicão à futura hérnia. Assim, pode ser efetuada abordagem e sutura de reforço como medida profilática no lado predisposto. Aliás, a redução bilateral simultânea, nos casos aqui descritos, não comprometeu o esfíncter externo do ânus, uma preocupação de autores como CANFIELD; BELLENGER ${ }^{5}$ (1985) e BOJRAB; TOOMEY ${ }^{4}$ (1986)

A prevalência da hérnia perineal foi maior em animais com idade entre 5 e 8 anos ( 20 cães), sendo que em 10 deles a idade (5-6 anos) foi inferior àquela citada por diferentes autores $^{6,13,14}$. A prevalência diminuiu proporcionalmente com a idade, a partir dos 8 anos, provavelmente pela procura de tratamento em período relativamente curto, após o surgimento da patologia (Tab. I c 2) e pela morbidade das complicaçōes que levam a óbito se não tratadas precocemente.

Pela anamnese foi constatado que a queixa mais frequiente foi o tenesmo com disquesia ou estrangúria, além de aumento de volume uni ou bilateral em árca perineal. Estes sinais são comuns àqueles citados na litcratura revisada ${ }^{4,6,11,13,14}$

A bexiga foi conteúdo herniário mais encontrado (60\%). Nos cães cm que estava retroflexionada (Tab. I e 2) o cateterismo, citado por SPICCIATI ${ }^{13}$ (1971). não toi possível em 4 deles. Nestes foi necessária cistocentese, drenagem da urina e redução da bexiga para a cavidade abdominal, pela taxe indireta, para ser conseguida a sondagem uretro-vesical. Considera-se que a drenagem da urina e o controle da uremia efetuado nos animais com esta complicação, como aliás recomendaram SPICCIATI ${ }^{13}$ (1971). CANFIELD; BELLENGER $^{5}$ (1985), BOJRAB: TOOMEY ${ }^{4}$ (1986), BILBREY et al. ${ }^{3}$ (1990), é fundamental para permitir a cirurgia em um paciente com quadro sistêmico compensado.

A próstata esteve aumentada de volume em cinco cães com hérnia bilateral e em sete unilateral (Tab. 1 e 2). Foram encontrados. ainda. divertículo retal em cinco cães e dilatação $\mathrm{em}$ quatro. O epíploo foi identilicado $\mathrm{em}$ dois cães e nódulos de tecido adiposo, de coloração escura ou necrosado em dezenove. Sete animais cvidenciaram cfusão serosa e serossangüínea. Como se obscrva. o contcúdo encontrado não difere daquele citado por diferentes autores ${ }^{4,6,14}$. A presença de efusão e nódulos de tecido adiposo alterado são indicação de encarceramento e compressão que podem trazer transtornos sistêmicos dependendo do órgão comprometido.

Para abordagem da hérnia perineal foi adotado o decúbito dorsal, conforme foi feito por SPICCIATI ${ }^{13}$ (1971) e não o esterno-abdominal recomendado por outros autores ${ }^{2,4,5}$. O decúbito dorsal com os membros pélvicos tracionados cranialmente determina um grau máximo de afastamento entre o músculo esfíncter externo do ânus co ligamento sacrotuberal. Desta forma, a sutura é adaptada de modo a oferecer sustentação contra um grau de tensão superior ao apresentado pelo períneo quando o animal estiver em outras posiçōes. Acredita-se que esta medida que oferece hemioplastia efetiva. como recomendou MATERA ${ }^{11}$ (1975), tenha contribuído para o baixo índice de recidiva ipsolateral $(8,5 \%)$ comparado aos dados observados por BELLENGER ${ }^{2}$ (1980) e KAUTH ${ }^{8}$ (1985) que foram $15,4 \%$ e $29,0 \%$.

A excisão proctoplástica na vigência de divertículo e a proctorrafia nas dilatações foram condutas adotadas para prevenir o tenesmo pós-cirúrgico que, de acordo com 


\section{TABEI.A 1}

Herniorralïa perineal bilateral. Prevalência conlorme a raça, idade, peso, período de evolução, conteúdo/complicação, traltamento e resultado em cães machos registrados no Hospital de Clínicas Veterinárias da Universidade Federal de Santa Maria. entre janciro de 1980 e dezembro de 1992

\begin{tabular}{|c|c|c|c|c|c|c|}
\hline Raça & Idade & $\begin{array}{l}\operatorname{Peso} \\
(\mathrm{kg})\end{array}$ & $\begin{array}{l}\text { Período } \\
\text { evolução }\end{array}$ & Contéudo/Complicação & Tratamento & Resultado \\
\hline SRI) & $8.0 \mathrm{a}$ & 12.0 & $2 \mathrm{ml}$ & bexiga/uremia & cutanásia & - \\
\hline SRI) & $6.1) \mathrm{a}$ & 7.8 & $8 m$ & bexiga, intestino & herniorrafial & $s / c$ \\
\hline SRI) & $8.1) \mathrm{al}$ & 10.5 & $2 \mathrm{~m}$ & bexiga/uremia & eutanásia & - \\
\hline SRI) & $5.0 \mathrm{a}$ & 6.0 & $s / i$ & tecido adiposo, intestino & herniorralial & $s / c$ \\
\hline SRI) & $5.0 \mathrm{a}$ & 11.0 & $3 \mathrm{~m}$ & $\begin{array}{l}\text { prostata aumentada, bexiga/ } \\
\text { clusão }\end{array}$ & $\begin{array}{l}\text { prostatectomia } \\
\text { e hermiorrallial }\end{array}$ & $s / c$ \\
\hline SRI) & $1.3 .0 \mathrm{a}$ & 7.2 & $3 d$ & $\begin{array}{l}\text { bexiga, próstata com cistos/ } \\
\text { uremial }\end{array}$ & $\begin{array}{l}\text { prostalectomia } \\
\text { e herniorrafia }\end{array}$ & $\begin{array}{l}\text { recidival } \\
\text { em } 42 d\end{array}$ \\
\hline SRI) & $10.0 \mathrm{a}$ & 16.0 & $4 m$ & $\begin{array}{l}\text { bexiga retroflexionada. diverriculo } \\
\text { retal }\end{array}$ & $\begin{array}{l}\text { proctoplastia } \\
\text { e herniorrafia }\end{array}$ & $s / c$ \\
\hline$S R I)$ & $8.0 \mathrm{al}$ & 9.5 & $s / j$ & bexiga, tecido adiposo necrosado & herniorrafia & $s / c$ \\
\hline SRI) & $0.0 ; 1$ & 9.5 & $2 m$ & $\begin{array}{l}\text { bexiga retroflexionadal próstata } \\
\text { com cistos/uremia }\end{array}$ & $\begin{array}{l}\text { prostatectomial } \\
\text { e herniorralial }\end{array}$ & $\begin{array}{l}\text { óbito cm } \\
\operatorname{lm}\end{array}$ \\
\hline SRI) & $5 .(1) a$ & 8.0 & $2 d$ & divertículo retal. intestino & procioplastia & $s / c$ \\
\hline SRI) & $7.0 \mathrm{al}$ & 16.0 & $s / i$ & bexigar tecido adliposo/clusão & herniorralia & $s / c$ \\
\hline SRI) & $14.0 \mathrm{a}$ & 18.0 & $45 d$ & $\begin{array}{l}\text { bexiga próstatal com cistos e leci- } \\
\text { do adiposo }\end{array}$ & $\begin{array}{l}\text { prostalcclomia } \\
\text { c herniorratial }\end{array}$ & $s / c$ \\
\hline BOXER & $8.0 \mathrm{al}$ & 12.0 & $2 m$ & $\begin{array}{l}\text { bexigat retroflexionada, intestino/ } \\
\text { efusion }\end{array}$ & herniorrallial & $s / c$ \\
\hline BOXER & $8.0 \mathrm{a}$ & 18.0 & $4 m$ & $\begin{array}{l}\text { bexiga, próstalat aumentada e tecido } \\
\text { adiposo }\end{array}$ & $\begin{array}{l}\text { prostatectomial } \\
\text { e herniorraltia }\end{array}$ & $s / c$ \\
\hline COLIII: & $10.0 \mathrm{al}$ & 27.0 & $8 d$ & bexiga, alçà intestinal/efusão & herniorrallia & $s / c$ \\
\hline PEQLIINIAS & 8.011 & 5.4 & $s / i$ & hexiga/uremial & herniorraliia & $s / c$ \\
\hline PEQUINIES & $9.5 a$ & 12.0 & $\mathrm{Im}$ & divertículo retal, alça intestinal & $\begin{array}{l}\text { proctoplastia c } \\
\text { herniorrafia }\end{array}$ & $s / c$ \\
\hline PEQUINÊ:S & $9.0 \mathrm{a}$ & 10.5 & $\operatorname{lm}$ & divertículo retal. alça intestinal & $\begin{array}{l}\text { procloplastial } \\
\text { herniorrafia }\end{array}$ & $s / c$ \\
\hline POINTER & $6,0 \mathrm{a}$ & 23.5 & $\operatorname{lm}$ & bexiga, lecido adiposo/clusão & herniorratia & $s / c$ \\
\hline $\mathrm{FOX}$ & $6,0 a \mathrm{a}$ & 6,2 & $6 m$ & bexiga $c$ alça intestinal & herniorrafia & $s / c$ \\
\hline
\end{tabular}

\footnotetext{
SRI = Sem Raça Definida

$s / i=\operatorname{sem}$ informaçãa

s/c = sem complicalçào

$\mathrm{d}=$ dia: $m=$ mês: $\mathrm{a}=\mathrm{ano}$
} 
TABELA 2

Herniorrafia perineal unilateral. Prevalência conforme a raça, idade, peso, periodo de evolução, localização, conteúdo/ complicação, tratamento e resultado em cães registrados no Hospital de Clínicas Veterinárias da Universidade Federal de Santa Maria, entre janeiro de 1980 e dezembro de 1992.

\begin{tabular}{|c|c|c|c|c|c|c|c|}
\hline Raça & Idade & $\begin{array}{l}\text { Peso } \\
(\mathrm{kg})\end{array}$ & $\begin{array}{l}\text { Período } \\
\text { cvolução }\end{array}$ & $\begin{array}{l}\text { Localização } \\
\text { (lado) }\end{array}$ & Conteúdo/Complicação & Tratamento & Resultado \\
\hline SRD & $12,0 \mathrm{a}$ & 12.0 & $2 a$ & esquerdo & $\begin{array}{l}\text { bexiga retroflexionada e prós- } \\
\text { tata com cistos }\end{array}$ & $\begin{array}{l}\text { prostatectomia } \\
\text { e herniorrafia }\end{array}$ & $\mathrm{s} / \mathrm{c}$ \\
\hline SRD & $12.0 \mathrm{a}$ & 15.0 & $6 \mathrm{~m}$ & esquerdo & $\begin{array}{l}\text { alça intestinal, próstata au- } \\
\text { mentada de volume }\end{array}$ & $\begin{array}{l}\text { herniorrafia e } \\
\text { orquiectomial }\end{array}$ & $\mathrm{s} / \mathrm{c}$ \\
\hline SRD & $11,0 \mathrm{a}$ & 17.8 & $2 a$ & direito & $\begin{array}{l}\text { bexiga retroflexionada e prós- } \\
\text { tata com cistos }\end{array}$ & $\begin{array}{l}\text { prostatectomia } \\
\text { e herniorrafia }\end{array}$ & $s / c$ \\
\hline SRD & $12,0 \mathrm{a}$ & 15,0 & la & direito & $\begin{array}{l}\text { divertículo retal,alça intes- } \\
\text { tinal/hémia contra-lateral } \\
\text { lm após redução }\end{array}$ & $\begin{array}{l}\text { proctoplastia } \\
\text { e hemiorrafia }\end{array}$ & $\mathrm{s} / \mathrm{c}$ \\
\hline SRD & $8,0 \mathrm{a}$ & 12,0 & $8 \mathrm{~m}$ & direito & divertículo retal & $\begin{array}{l}\text { proctoplastia c } \\
\text { herniorrafia }\end{array}$ & $s / c$ \\
\hline SRD & $6,0 \mathrm{a}$ & 16,0 & $45 d$ & esquerdo & dilatação retal & $\begin{array}{l}\text { proctorratia e } \\
\text { herniorrafia }\end{array}$ & $\mathrm{s} / \mathrm{c}$ \\
\hline SRD & $12,0 \mathrm{a}$ & 14,0 & $9 \mathrm{~m}$ & esquerdo & $\begin{array}{l}\text { epíploo, tecido adiposo/efusão, } \\
\text { hérnia contra-lateral } 5 \mathrm{~m} \text { depois }\end{array}$ & herniorrafia & $\mathrm{s} / \mathrm{c}$ \\
\hline PEQUINES & $6,0 \mathrm{a}$ & 6,5 & $s / i$ & esquerdo & alça intestinal & herniorrafia & $\mathrm{s} / \mathrm{c}$ \\
\hline PEQUINÊS & $9.0 \mathrm{a}$ & 12,0 & $45 d$ & direito & $\begin{array}{l}\text { alça intestinal, próstata au- } \\
\text { mentada de volume/recidiva } \\
\mathrm{cm} 1 \mathrm{~m}\end{array}$ & $\begin{array}{l}\text { herniorrafia } \\
\text { e orquiectomia }\end{array}$ & eutanásia \\
\hline PEQUINÊS & $10,0 \mathrm{a}$ & 10,2 & $s / i$ & direito & $\begin{array}{l}\text { dilatação retal, tecido adipo- } \\
\text { so/efusão }\end{array}$ & $\begin{array}{l}\text { proctorrafia e } \\
\text { herniorrafia }\end{array}$ & $\mathrm{s} / \mathrm{c}$ \\
\hline PEQUINÊS & $13,0 \mathrm{a}$ & 12,0 & $8 \mathrm{~m}$ & esquerdo & $\begin{array}{l}\text { bexiga retroflexionada e prós- } \\
\text { tata com cistos }\end{array}$ & $\begin{array}{l}\text { prostatectomia } \\
\text { e herniorrafia }\end{array}$ & $\mathrm{s} / \mathrm{c}$ \\
\hline COLLIE & $5,0 \mathrm{a}$ & 30,0 & $6 \mathrm{~m}$ & direito & $\begin{array}{l}\text { dilatação retal, próstata com } \\
\text { cistos/uremia }\end{array}$ & $\begin{array}{l}\text { prostatectomia } \\
\text { e proctorrafia }\end{array}$ & $\begin{array}{l}\text { óbito em } \\
24 \mathrm{~h}\end{array}$ \\
\hline $\begin{array}{l}\text { PASTOR } \\
\text { ALEMÃOO }\end{array}$ & $8,0 \mathrm{a}$ & 28,0 & $s / i$ & direito & $\begin{array}{l}\text { alça intestinal, epíploo/hér- } \\
\text { nia contra-lateral em } 75 \mathrm{~d}\end{array}$ & herniorrafia & $s / c$ \\
\hline $\begin{array}{l}\text { PASTOR } \\
\text { ALEMÃO }\end{array}$ & $7,0 \mathrm{a}$ & 32,0 & $5 \mathrm{~m}$ & esquerdo & dilatação retal, alça intestinal & $\begin{array}{l}\text { proctorrafia e } \\
\text { herniorrafia }\end{array}$ & $\mathrm{s} / \mathrm{c}$ \\
\hline $\begin{array}{l}\text { PASTOR } \\
\text { BELGA }\end{array}$ & $10.0 \mathrm{a}$ & 27,0 & $6 \mathrm{~m}$ & esquerdo & $\begin{array}{l}\text { bexiga e próstata aumentada de } \\
\text { volume }\end{array}$ & $\begin{array}{l}\text { herniorrafia e } \\
\text { orquiectomia }\end{array}$ & $s / c$ \\
\hline
\end{tabular}

SRD = Sem Raça Definida

$\mathrm{s} / \mathrm{i}=$ sem informação

$\mathrm{s} / \mathrm{c}=$ sem complicação

$\mathbf{h}=$ hora; $\mathrm{d}=$ dia; $\mathrm{m}=$ mês; $\mathbf{a}=$ ano 
KRAHWINKEL ${ }^{9}$ (1983) e WHITE: HERRTAGE ${ }^{14}$ (1986), é a principal causa de recidivas. Este procedimento é recomendado, mesmo que se consiga adequada redução da abertura herniária, pois, em razão da idade, os tecidos da região perineal são muito frágeis. Fatores que prejudiquem o trânsito digestivo, como o divertículo ou a dilatação, favorecem a recidiva. Durante a sutura procurou-se evitar que os pontos invadissem o lume do reto para prevenir eventual formação de fístulas. Não foram noticiadas complicações no acompanhamento por até 4 anos.

Ao contrário de SPICCIATI ${ }^{13}$ (1971) que efetuou a excisão da próstata sempre que estivesse aumentada de volume, nos casos aqui relatados foi feita orquiectomia quando a próstata apresentasse simples aumento de volume e prostatectomia na presença de cistos (Fig. 3), que o posterior estudo anatomohistopatológico revelou ser hiperplasia cística. As duas técnicas foram usadas como alternativas porque, segundo MANN et al. ${ }^{10}$ (1989), não existe comprovaçāo de que hormônios sexuais masculinos atuem sobre os músculos da pelve no animal adulto. Considera-se, então, que se a influência for sobre a próstata, como citaram ARCHIBALD; SUMNERSMITH' (1974), a excisão de uma glândula ou outra seja suficiente.

Para redução da hérnia perineal foram utilizados fio mononáilon (18 cães), poliéster trançado siliconizado (8 cães), categute cromado ( 5 cães) e ácido poliglicólico ( 1 cão). Ocorreram duas recidivas ipsolaterais em cães cuja sutura fora feita com categute. Estes resultados demonstram que o categute não oferece sustentação por tempo suficiente para a cicatrização, embora a literatura ${ }^{2,4,5.6}$ dê preferência a cle, por determinar reação inflamatória mais prolongada. Assim, haveria maior grau de fibrose e, portanto, mais resistência. Nos cães aqui analisados preferiu-se fios inabsorvíveis, principalmente nos mais idosos, pois são pacientes que apresentam cicatrização retardada $\mathrm{e}$, assim, predispostos à recidiva.

O esquema antibacteriano utilizado, que iniciou no préoperatório, estendendo-se por até 7 dias após a cirurgia, difere daquele indicado por BELLENGER ${ }^{2}$ (1980) que usou antibiótico somente no pós-operatório. O protocolo aqui empregado permite que durante a cirurgia, os tecidos já apresentem concentração inibitória mínima do antibiótico prevenindo a implantação de agentes contaminantes. A utilização póscirúrgica do antibiótico prolonga a proteção contra infecção, numa área considerada de alto risco de contaminação. A ausência de infecção pós-operatória, nos casos aqui apresentados, comprovam a eficiência do método.

Três cães foram submetidos à eutanásia (Tab. 1 e 2) por solicitação dos proprietários, tendo $\mathrm{cm}$ vista a gravidade do quadro clínico. Dos cães que foram a óbito, um (Tab. 2) foi $\mathrm{cm}$ consequiência de choque hipovolêmico. No outro (Tab. 1) não foi identificada a possível causa.

\section{CONCIUSÕES}

Considerando os resultados obtidos pode-se concluir que:

a) na abordagem de hérnia perineal unilateral deve ser avaliado cuidadosamente o lado oposto, para corrigir eventual predisposição e recidiva contra-lateral;

b) quando a próstata hemiada apresentar apenas aumento de volume pode ser associada à orquiectomia e à redução da hérnia perineal. Na presença de cistos associar à prostatectomia;

c) a proctoplastia para corrigir divertículo e a proctorrafia para corrigir dilatação estão recomendadas como prevenção à recidiva de hérnia perineal;

d) o posicionamento do animal em decúbito dorsal, com os membros tracionados cranialmente, permite definir áreas de efetiva sustentação aos pontos de sutura, na redução de hérnia perineal;

e) o uso de fio não absorvível, particularmente o mononáilon oferece sustentação estrutural adequada à redução de hérnia perineal, sendo o mais indicado pelo potencial risco de contaminação na área, e

f) a irrigação abundante da ferida cirúrgica. com solução salina isotônica durante o ato operatório, associada ao uso profilático-terapêutico da ampicilina, mostra-se eficiente no controle da infeç̧ão cirúrgica, na redução de hérnia perineal.

\section{SUMMARY}

During a twelve-year period, from January 1980 to December 1992, 35 male dogs with perineal hernia were managed by the author. These dogs were submitted to the Veterinary Teaching Hospital (VTH). Universidade Federal de Santa Maria, RS. Brazil. The prevalence of herniation represented $0.5 \%$ of the dogs and cats seen at VTH in this period. The complications diagnosed were as the follow: retroflexion of the urinary bladder, rectal dilatation or diverticulum. necrotic retroperitoneal fat and serum or serosanguineous effusion. The surgical efficiency are dependent of digestive and urinary patency, obliteration of the perineal opening and control of tenesmus and infection.

UNITERMS: Hernia; perineum; surgery; dogs; herniorrhaphy 


\section{REFERÊNCIAS BIBLIOGRÁFICAS}

01-ARCHIBALD. J.; SUMNER-SMITH, G. Abdomen. In: ARCHIBALD, J. Canine Surgery. 2.ed. Santa Barbara. Amer. Vet. Public., 1974. p.505-54.

02-BELlengeR. C.R. Perineal hernia in dogs. Australian Veterinary Journal, v.56, n.9, p.434-8, 1980.

03-BILBREY, S.A.; SMEAK. D.D.; DEHOFF, W. Fixation of the deferent ducts for retrodisplacement of the urinary bladder and prostate in canine perineal hernia. Veterinary Surgery, v.19, n.1, p.24-7, 1990.

04-BOJRAB, M.J.: TOOMEY. A.A. Hérnias - hérnia perineal. In: BOJRAB, M.J. Cirurgia dos pequenos animais. São Paulo, Rocca, 1986. Cap.30. p.436-41.

05-CANFIELD. R.B.; BELLENGER. C.R. Perineal hernia. In: SLATTER, D.H. Texthook of small animal surgery. Philadelphia, W.B. Saunders, 1985. Cap.60. p.436-41.

06-DALECK, C.R.; DALECK, C.L.M.; PADILHA FILHO, J.G.; COSTA NETO, J.M. Reparação de hérnia perineal em cães com peritônio bovino conservado em glicerina. Ciência Rural, v.22, n.2, p.179-83, 1992.

07-JOHNSTON, D.E.; ARCHIBALD, J. Male genital system. In: ARCHIBALD. J. Canine Surgery. Santa Barbara, Amer. Vet. Publ., 1974. Cap.16, p.743-9.

08-KAUTH, E.M. Zur hernia perinealis beimhund. Behandling und ergebins in den jahren, 1978-1982. Munchen, 1985. (Inaugural dissertation)Terararzlliche Fakultat der Ludwig-MaximiliaUniversitat Munchen.
09-KRAHWINKEL, D.J. Rectal discases and their role in perineal hernia. Veterinary Surgery, v. 12, n.3, p. 160 $5,1983$.

10-MANN, F.A.; BOOTHE, H.W.: AMOSS, M.S.; TANGNER, C.H.; PUGLISI, T.A.; HOBSON, H.P. Serum testosterone and estradiol 17-beta concentrations in 15 dogs with perineal hernia. Journal of the American Veterinary Medical Association, v.194, n.11, p.1578-80, 1989

11-MATERA. E.A. I.ições de patologia cirúrgica geral. 3.ed. Bclo Horizonte, 1975.

12-MICHELL. A.R.; BYWATER, R.J.; CLARK, K.W.; HALL. L.W. Fluidoterapia Veterinaria. Zaragoza, Acribia, 1991. Cap.5: Valoracion clinica y de laboratorio de las deficiencias y alteraciones, p.91109.

13-SPICCIATI, W. Contribuição para o estudo do tratamento cirúrgico da hérnia perincal com prostatectomia no cão. Revista da Faculdade de Medicina Veterinária, São Paulo, v.8, n.3, p.771-806. 1971

14-WHITE, R.A.S.; HERRTAGE, M.E. Bladder retroflexion in the dog. Journal of Small Animal Practice, v.27, n.11, p.735-46. 1986.

Recebido para publicacão em: 16/06/93 Aprovado para publicacão em: 23/11/93 